\title{
ASPEK-ASPEK YANG BERDAMPAK TERHADAP KESUKSESAN PRODUK SUATU TINJAUAN LITERATUR KRITIS
}

\author{
Trifandi Lasalewo \\ Jurusan Teknik Industri, Universitas Negeri Gorontalo \\ Email: trifandilasalewo@ung.ac.id
}

\begin{abstract}
ABSTRAK
Kesuksesan perusahaan sangat dipengaruhi oleh kesuksesan produk-produk yang dihasilkannya. Indikator kesuksesan produk ditunjukkan oleh kinerjanya, seperti kemampuannya menghasilkan profit, sales yang tinggi, market share yang baik, atau payback period yang relatif singkat. Namun, dari banyak produk yang berhasil dikembangkan perusahaan melalui proyek penelitian yang mahal, lama, dan beresiko, hanya sedikit yang benarbenar sukses saat tiba di pasar.

Studi ini bertujuan untuk membangkitkan aspek-aspek yang berdampak langsung terhadap kesuksesan produk, melalui studi literatur yang mendalam dan sistematis, terutama melalui studi meta-analisis. Hasil dari studi ini memperoleh lima aspek yang berkorelasi dengan kesuksesan produk, yakni product characteristics, management \& organizational characteristics, marketplace characteristics, innovation dan knowledge sharing, yang terdiri atas dua puluh prediktor. Kelima aspek dan dua puluh prediktor ini, dapat digunakan sebagai model rujukan dalam rangka pengembangan produk baru dimasa yang akan datang.
\end{abstract}

Kata kunci: produk sukses, studi meta-analisis, tinjauan literatur kritis

ABSTRACT

A company's success is greatly influenced by the success of its products. The success indicators of a product are indicated by its performance, including its ability to generate profits, high sales, good market share, and relatively short payback period. However, of the numerous products successfully developed by companies through expensive, long-term, and risky research projects. Only a few are truly successful when they arrive on the market.

This study was aimed to generate facet that has a direct impact on product success through an in-depth and systematic literature review, especially through a meta-analysis study. The analysis results suggested five aspects that correlated with the product success, i.e. product characteristics, management \& organizational characteristics, marketplace characteristics, innovation, and knowledge sharing, which consisted of twenty predictors. These five aspects and twenty predictors can be used as a reference model in the context of developing new products in the future.

\section{Keywords: successful product, meta-analysis study, systematic literature review}

\section{PENDAHULUAN}

Produk sukses menjadi orientasi dari setiap perusahaan, baik perusahaan manufaktur maupun perusahaan jasa. Kesuksesan produk menjadi salah satu indikator kesuksesan perusahaan, sehingga berbagai upaya dilakukan oleh perusahaan agar dapat menghasilkan produk-produk yang sukses, baik upaya secara teknis maupun secara administratif. Adanya produk sukses, perusahaan dapat meningkatkan pendapatannya lebih dari $25 \%$ dalam waktu tiga sampai lima tahun (Calantone et al., 1996). Adanya produk sukses, maka akan berdampak terhadap kesuksesan perusahaan sebagai penghasil produk tersebut (Cooper, 2007; Schilling, 2013).

Produk sukses adalah produk yang memiliki kinerja baik, antara lain ditunjukkan oleh kemampuannya menghasilkan profit (keuntungan), sales (tingkat penjualan produk) dan market share (penguasaan pasar) yang baik, serta payback period yang relatif singkat. Keberhasilan suatu produk umumnya diukur menggunakan tiga dimensi, yakni financial peformance (kinerja finansial), opportunity window (peluang keberhasilan), dan market impact (dampak produk terhadap pasar sasaran) (Cooper \& Kleinschmidt, 1987a, 1987b).

Pada kenyataannya, tidak semua produk dihasilkan oleh perusahaan, akan berakhir dengan kesuksesan. Pengembangan produk baru, sesungguhnya memiliki resiko yang sangat tinggi, mahal dan tidak ada jaminan akan sukses di pasar (Junfeng \& Wei-Ping, 2017). Pada survei yang dilakukan oleh Project NewProd menunjukkan bahwa setiap 100 produk yang dikembangkan oleh perusahaan, sekitar $21,9 \%$ mengalami kegagalan ketika diluncurkan, 18,7\% mengalami kegagalan ketika sampai di pasar, dan hanya 59,4\% yang dapat sukses di pasar (Cooper, 1980). Survei Product Development and Management Association (PDMA) juga mengungkapkan, rata-rata kegagalan 
produk baru mencapai $41 \%$, dan rata-rata hanya 1 dari 6,6 produk yang dihasilkan, yang akan sukses di pasar (Lin, 2007).

Dilain sisi, proyek pengembangan produk baru membutuhkan waktu yang sangat lama, mahal, dan sangat beresiko. Misalnya pada industri farmasi, dibutuhkan waktu sedikitnya 15 tahun, dari penemuan hingga peluncuran sebuah obat ke pasar, dan hanya satu dari setiap 5.000 senyawa yang akan menghasilkan produk obat baru (Schilling, 2013). Pada studi yang dilakukan Urban (1980) menunjukkan bahwa 35\% hingga $44 \%$ dari total produk yang diperkenalkan produsen kepada konsumen merupakan produk gagal (Bouchereau \& Rowlands, 2000).

Pada proyek pengembangan produk baru komersil, diperkirakan hanya satu dari empat proyek pengembangan yang sukses, dan terdapat sepertiga dari semua produk baru diluncurkan gagal di pasar (Cooper, 2007). Berdasarkan pengamatan Cooper (2007), diperkirakan sebanyak $46 \%$ sumber daya perusahaan dialokasikan untuk biaya penelitianpengembangan dan launching produk baru yang pada akhirnya tidak sukses di pasar.

Penelitian yang dilakukan ini bertujuan untuk melakukan critical review atas aspek-aspek apa saja yang memiliki dampak terhadap kesuksesan produk. Sumber-sumber rujukan, terutama berasal dari penelitian meta-analysis study sebelumnya, karena lebih bersifat kuantitatif. Adapun case study pada penelitian-penelitian produk sukses sebelumnya, dijadikan sebagai referensi tambahan agar menghasilkan suatu bahan analisis yang lebih komprehensif.

\section{METODE PENELITIAN}

Proses untuk melakukan studi literatur mengikuti standar Systematic Literature Review (SLR) yang direkomendasikan oleh Jesson, Matheson, \& Lacey (2011). Proses mereview literatur melalui tiga fase utama, yakni (1) mengumpulkan berbagai referensi yang berkaitan dengan produk sukses; (2) memilih kesuaian referensi berdasarkan kriteria judul, abstrak, dan kata kunci; (3) memilih referensi utama yang digunakan dalam studi literatur. Langkah-langkah standar SLR ini diringkas dalam Gambar 1.

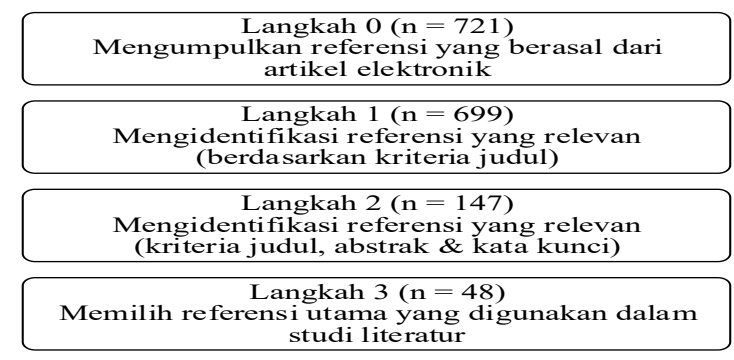

Gambar 1. Langkah-langkah pemilihan referensi
Sumber data literatur, berasal dari berbagai sumber terpercaya yakni: ScienceDirect (Elsevier), Springer Link, EmeraldInsight, Scopus, IEE Electronic Library, serta ProQuest. Untuk mempermudah proses pencarian dan pemetaan penelitian, misalnya pada data Scopus, menggunakan alat bantu software VOSviewer. Pemetaan dengan menggunakan aplikasi ini, menghasilkan gambaran mengenai topik-topik penelitian yang berkorelasi dengan produk sukses.

Proses pencarian awal data elektronik (langkah 0) ini menemukan 721 dokumen yang berhubungan dengan produk sukses. Proses mengidentifikasi referensi yang relevan (langkah 1) berdasarkan kriteria judul menemukan 699 dokumen. Pencarian selanjutnya kemudian diperkecil pada keywords saja (langkah 2) dan hasilnya menemukan 147 dokumen. Topik penelitian yang sering muncul antara lain product design, innovation, product development, NPD project, customer satisfaction, competition, sales, product performance, dan customer need. Data temuan ini kemudian dianalisis sebagai referensi utama (langkah 3), dan dihasilkan 48 dokumen artikel yang berkaitan langsung dengan kesuksesan produk.

Proses pemilihan literatur, dilakukan untuk memilih sumber manasaja yang dapat digunakan sebagai literatur utama, dan mana sebagai literatur pembanding atau pendukung. Proses seleksi literatur dilakukan dengan kriteria: (1) diutamakan publikasi 10 tahun terakhir; (2) artikel bersumber dari jurnal internasional terpercaya (bereputasi), dan electronically available (tersedia dalam bentuk artikel elektronik); (3) pemilihan artikel terutama berisikan aspek/variabel yang memiliki korelasi langsung terhadap kesuksesan produk; (4) prioritas pemilihan literatur utama adalah publikasi penelitian yang menggunakan studi meta-analisis sebagai alat ukurnya. Adapun tujuan utama dilakukan systematic literature review ini adalah untuk menemukan aspek/variabel-variabel apa saja yang berdampak terhadap kesuksesan produk.

\section{HASIL DAN PEMBAHASAN}

Berdasarkan studi literatur secara mendalam (terutama studi meta analisis) ditemukan beberapa aspek (variabel) yang mempengaruhi kesuksesan produk. Studi meta analisis korelasi yang dilakukan pada penelitian ini bertujuan untuk menguji hubungan antara variabel-variabel penelitian yang telah dilakukan pada penelitian-penelitian sebelumnya terhadap produk sukses. Bentuk korelasi studi meta analisis terhadap produk sukses, dijelaskan pada Gambar 2. 


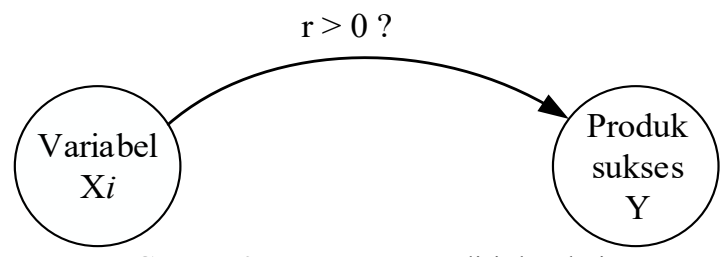

Gambar 2. Konsep meta-analisis korelasi

Meta analisis korelasi bertujuan untuk mendapatkan distribusi sesungguhnya dari korelasi antara suatu variabel independen dengan variabel dependen (Hunter \& Schmidt, 2004). Adapun variabel independen $X$ dalam penelitian ini adalah variabel-variabel yang memiliki dampak terhadap kesuksesan produk, sedangkan variabel dependen $Y$ adalah produk sukses.

\subsection{Studi-studi Meta-analisis tentang Kesuksesan Produk}

Beberapa studi meta analisis berhasil mengidentifikasi aspek/variabel yang berkorelasi dengan kesuksesan produk, antara lain:

Studi meta analisis Henard \& Szymanski (2001) menggunakan 60 studi empiris, berhasil mengidentifikasi empat aspek, yakni product characteristics, firm strategy characteristics, firm process characteristics, dan marketplace characteristics. Studi meta analisis Evanschitzky et al. (2012) dengan menggunakan 233 studi empiris, berhasil mengidentifikasi lima variabel, yakni product characteristics, strategy characteristics, process characteristics, marketplace characteristics, dan organizational characteristics. Pada studi meta analisis Huang \& Tsai (2013) ditemukan lima variabel yakni strategy, product effectiveness, organization, process, dan environment. Studi meta analisis Eisend et al. (2016) menemukan relative advantage (terdiri atas prediktor marketing dan technological capability) sebagai variabel yang mempengaruhi new product success (dinyatakan sebagai new product performance), sedangkan Cankurtaran et al. (2013) dan Gao et al. (2013) menemukan new product development speed sebagai variabel yang berkorelasi dengan kesuksesan produk. Hasil analisis mendalam terhadap studi meta analisis tentang variabel produk sukses sebelumnya, dijelaskan secara rinci pada Tabel 1.

Jika diamati lebih mendalam, beberapa variabel yang digunakan pada studi meta analisis, melibatkan prediktor yang sama. Misalnya, product characteristics menggunakan prediktor: product advantage, product meets customer needs, product price, dan product technological sophistication.
Variabel dan prediktor produk sukses, pada studistudi meta analisis sebelumnya tersebut, selanjutnya digunakan sebagai prediktor dalam penelitian ini.

Berdasarkan studi komparasi pada studistudi meta analisis sebelumnya, terdapat 3 (tiga) variabel meta analisis yang sering digunakan untuk memprediksi kesuksesan produk, yakni product characteristics, management \& organizational characteristics, dan marketplace characteristics, seperti ditunjukkan oleh Gambar 3.

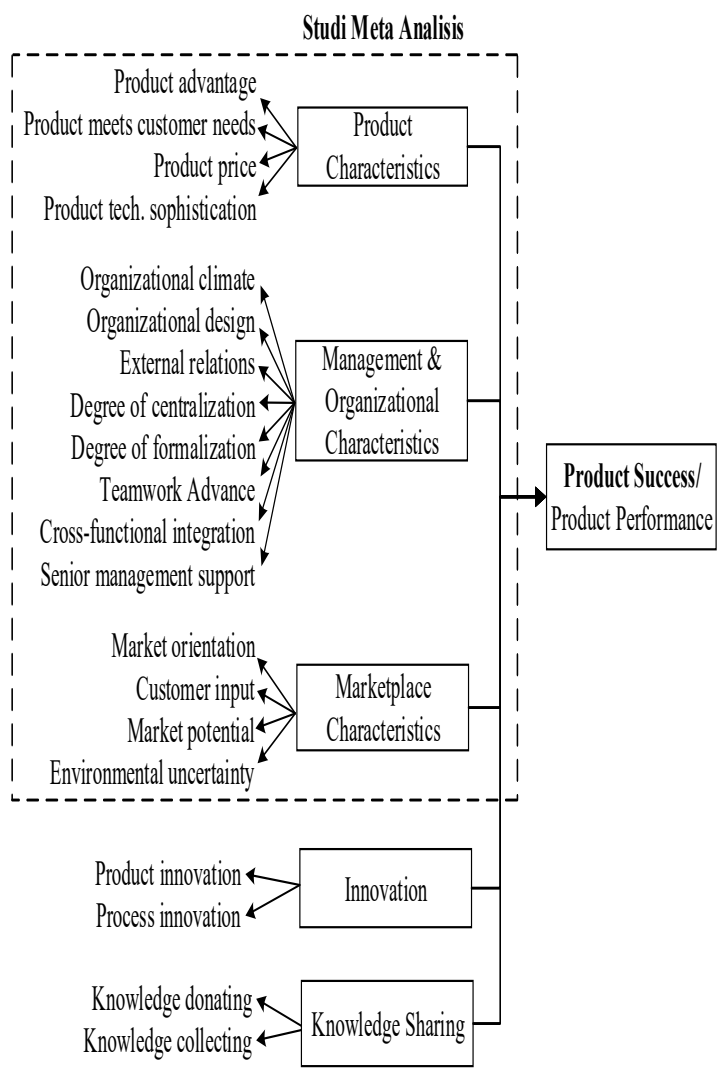

Gambar 3. Studi tentang kesuksesan produk

Aspek product characteristics (karakteristik produk) mencakup semua elemen (prediktor) yang berkaitan dengan karakter yang melekat pada produk, seperti product advantage, product meets customer needs, product price, dan product technological sophistication (Henard \& Szymanski, 2001; Evanschitzky et al., 2012; Cankurtaran et al., 2013; Huang \& Tsai, 2013; Fortuin et al., 2007; Langerak et al., 2004; Valle \& Vazquez-Bustelo, 2009; Storey \& Easingwood, 1996; Gonzalez \& Vazquez, 2007; Junfeng \& Wei-Ping, 2017; Lin, 2007). 
Tabel 1. Studi Meta-analisis terkait produk sukses

\begin{tabular}{|c|c|c|c|c|}
\hline Studi & Aspek yang dikaji & $\begin{array}{c}\text { Tujuan } \\
\text { Penelitian }\end{array}$ & $\begin{array}{c}\text { Metode analisis/ } \\
\text { Jumlah Studi/ Unit } \\
\text { analisis }\end{array}$ & $\begin{array}{l}\text { Temuan Penting } \& \\
\text { Rekomendasi }\end{array}$ \\
\hline $\begin{array}{l}\text { Cankurtar } \\
\text { an, } \\
\text { Langerak } \\
\text { \& Griffin } \\
(2013)\end{array}$ & $\begin{array}{l}\text { New Product Development } \\
\text { Speed: } \\
\text { 1. Development costs }(+) \\
\text { 2. Technical product } \\
\text { quality }(-) \\
\text { 3. Market entry timing }(+) \\
\text { 4. Product competitive } \\
\text { advantage }(+) \\
\text { 5. Customer based }(+) \\
\text { 6. Financial }(+) \\
\text { New product success } \\
\text { (overall): }+\end{array}$ & $\begin{array}{l}\text { Studi ini untuk } \\
\text { membuktikan } \\
\text { penelitian- } \\
\text { penelitian } \\
\text { sebelumnya, } \\
\text { bahwa } \\
\text { innovation } \\
\text { speed } \\
\text { berdampak } \\
\text { terhadap new } \\
\text { product success }\end{array}$ & $\begin{array}{l}\text { Metode analisis: } \\
\text { Meta-Analytic } \\
\text { Number of studies: } 75 \\
\quad \text { studies } \\
\text { Unit analisis: } \\
\text { Physical products } \\
\text { Same concept: } \\
\text { Time-to-market = } \\
\text { product development } \\
\text { time = innovation time = } \\
\text { lead time = project } \\
\text { completion time = total } \\
\text { time }\end{array}$ & $\begin{array}{l}\text { Penelitian ini menggunakan } \\
\text { metode meta-analisis untuk } \\
\text { memahami hubungan antara } \\
\text { new product development } \\
\text { speed dan new product } \\
\text { success dengan lebih rinci. } \\
\text { Hasil penelitian } \\
\text { mengindikasikan hubungan } \\
\text { positif signifikan antara } \\
\text { development speed dengan } \\
\text { overall new product success } \\
\text { constructs, namun technical } \\
\text { product quality tidak dapat } \\
\text { dijelaskan, apakah } \\
\text { berhubungan dengan } \\
\text { kesuksesan produk atau tidak. }\end{array}$ \\
\hline $\begin{array}{l}\text { Eisend, } \\
\text { Evanschit } \\
\text { zky \& } \\
\text { Calanton } \\
\text { e (2016) }\end{array}$ & $\begin{array}{l}\text { Relative Advantage: } \\
\text { 1. Marketing }(+) \\
\text { 2. Technological capability } \\
\quad(+) \\
\text { New product success = new } \\
\text { product performance }\end{array}$ & $\begin{array}{l}\text { Studi ini } \\
\text { dilakukan untuk } \\
\text { mengetahui } \\
\text { pengaruh } \\
\text { dominan antara } \\
\text { marketing } \\
\text { capability versus } \\
\text { technological } \\
\text { capability, } \\
\text { dalam konteks } \\
\text { kelembagaan di } \\
\text { suatu negara }\end{array}$ & $\begin{array}{l}\text { Metode: } \\
\text { 1. Meta-Analytic } \\
\text { 2. Hierarchical Linear } \\
\text { Model (HLM): } \\
\text { estimation procedure } \\
\text { for literature. } \\
\text { Number of studies: } \mathbf{5 0} \\
\text { articles ( } 17 \text { countries) }\end{array}$ & $\begin{array}{l}\text { Terdapat indikasi bahwa } \\
\text { capability (marketing dan } \\
\text { technology) memiliki } \\
\text { hubungan positif dengan new } \\
\text { product success. } \\
\text { Studi ini menunjukkan } \\
\text { marketing capability relatif } \\
\text { memberikan keuntungan, } \\
\text { dibandingkan technological } \\
\text { capability, dimana marketing } \\
\text { capability didefinisikan } \\
\text { sebagai kemampuan } \\
\text { memahami dan dapat } \\
\text { memprediksi kebutuhan } \\
\text { konsumen, lebih baik dari } \\
\text { kompetitor. }\end{array}$ \\
\hline $\begin{array}{l}\text { Suharyan } \\
\text { ti, } \\
\text { Subagyo, } \\
\text { Masruroh } \\
\text { \& Bastian } \\
(2015)\end{array}$ & $\begin{array}{l}\text { Independent Variables: } \\
\text { 1. Product characteristic } \\
(+)\end{array}$ & $\begin{array}{l}\text { Penelitian ini } \\
\text { untuk } \\
\text { mengidentifikasi } \\
\text { kontribusi } \\
\text { variabel-variabel } \\
\text { independen } \\
\text { terhadap } \\
\text { kesuksesan } \\
\text { produk. }\end{array}$ & $\begin{array}{l}\text { Metode analisis: } \\
\text { Meta-Analysis } \\
\text { Number of studies: } 166 \\
\quad \text { studies } \\
\text { (N= 30.759 samples) } \\
\text { Unit analisis: } \\
\text { Large industries \& } \\
\quad \text { SMEs } \\
\quad \text { (manufacturers } \\
\text { and services) }\end{array}$ & $\begin{array}{l}\text { Dari enam variabel yang } \\
\text { mempengaruhi kesuksesan } \\
\text { produk, lima variabel } \\
\text { berkorelasi positif. Hanya } \\
\text { variabel product development } \\
\text { cost yang tidak dapat } \\
\text { dibuktikan berkorelasi positif } \\
\text { dengan variabel kesuksesan } \\
\text { produk. } \\
\text { Hal ini mengindikasikan } \\
\text { bahwa biaya pengembangan } \\
\text { penelitian tidak dapat } \\
\text { dibuktikan berkorelasi dengan } \\
\text { kesuksesan produk. }\end{array}$ \\
\hline
\end{tabular}


Tabel 1. Studi Meta-analisis terkait produk sukses (Lanjutan)

\begin{tabular}{|c|c|c|c|c|}
\hline Studi & Aspek yang dikaji & $\begin{array}{c}\text { Tujuan } \\
\text { Penelitian }\end{array}$ & $\begin{array}{c}\text { Metode analisis/ } \\
\text { Jumlah Studi/ Unit } \\
\text { analisis }\end{array}$ & $\begin{array}{l}\text { Temuan Penting } \& \\
\text { Rekomendasi }\end{array}$ \\
\hline $\begin{array}{l}\text { Evansch } \\
\text { it, } \\
\text { Eisend, } \\
\text { Calanto } \\
\text { ne \& } \\
\text { Jiang } \\
(2012)\end{array}$ & 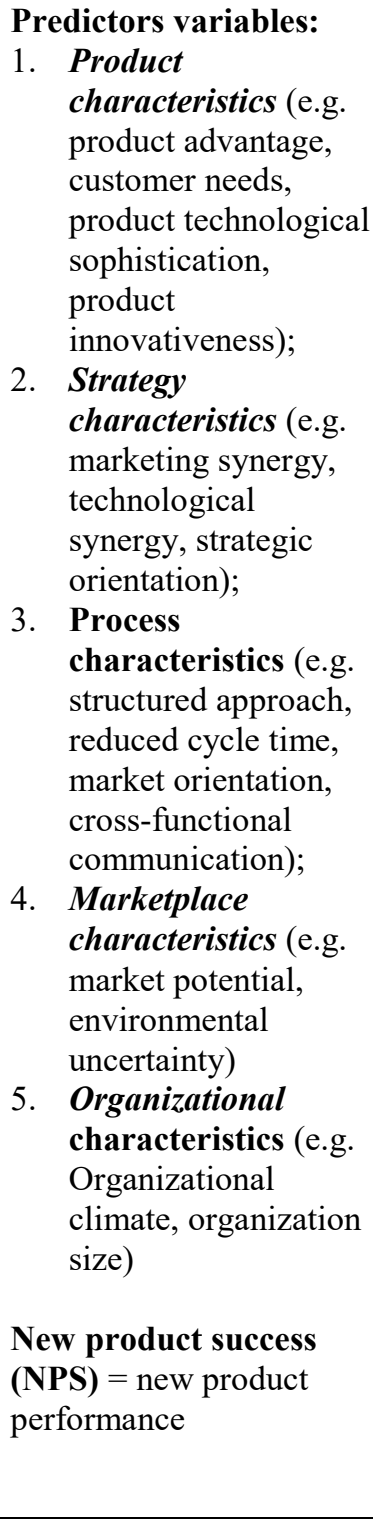 & $\begin{array}{l}\text { Melakukan } \\
\text { pemetaan } \\
\text { terhadap studi- } \\
\text { studi } \\
\text { sebelumnya } \\
\text { dan } \\
\text { membandingk } \\
\text { annya dengan } \\
\text { studi meta } \\
\text { analisis } \\
\text { Szymanski \& } \\
\text { Henard } \\
(2001) \text {. }\end{array}$ & 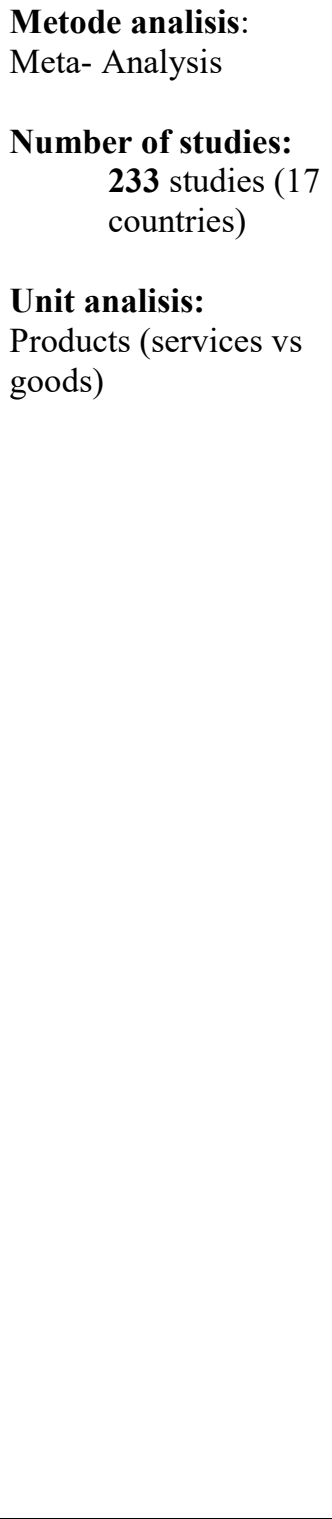 & $\begin{array}{l}\text { Memetakan hubungan } \\
\text { antara variabel prediktor } \\
\text { dan pengaruhnya } \\
\text { terhadap kinerja produk } \\
\text { baru (kesuksesan } \\
\text { produk baru), dimana } \\
\text { masing-masing variabel } \\
\text { prediktor memiliki sub- } \\
\text { variabel. Ukuran } \\
\text { pengaruh variabel } \\
\text { prediktor terhadap } \\
\text { kesuksesan produk baru, } \\
\text { diukur menggunakan } \\
\text { effect sizes. } \\
\text { Tiga variabel prediktor } \\
\text { yakni strategy } \\
\text { characteristics, process } \\
\text { characteristics, dan } \\
\text { marketplace } \\
\text { characteristics } \\
\text { signifikan pengaruhnya } \\
\text { terhadap NPS (New } \\
\text { Product Success). } \\
\text { Studi ini juga } \\
\text { memasukkan variabel } \\
\text { tambahan penting dalam } \\
\text { analisisnya yakni } \\
\text { "country culture", } \\
\text { dengan membandingkan } \\
\text { budaya Asia versus } \\
\text { Amerika/Eropa, dimana } \\
\text { bekerja dalam konteks } \\
\text { budaya bervariasi akan } \\
\text { menghasilkan perbedaan } \\
\text { kesuksesan produk yang } \\
\text { berbeda. }\end{array}$ \\
\hline
\end{tabular}


Tabel 1. Studi Meta-analisis terkait produk sukses (Lanjutan)

\begin{tabular}{|c|c|c|c|c|}
\hline Studi & Aspek yang dikaji & $\begin{array}{c}\text { Tujuan } \\
\text { Penelitian }\end{array}$ & $\begin{array}{c}\text { Metode analisis/ } \\
\text { Jumlah Studi/ Unit } \\
\text { analisis }\end{array}$ & $\begin{array}{l}\text { Temuan Penting \& } \\
\text { Rekomendasi }\end{array}$ \\
\hline $\begin{array}{l}\text { Gao, } \\
\text { Yu \& } \\
\text { Wu } \\
(2013)\end{array}$ & $\begin{array}{l}\text { New Product } \\
\text { Development Speed \& } \\
\text { New Product Success }\end{array}$ & $\begin{array}{l}\text { Melakukan } \\
\text { pengujian } \\
\text { hubungan } \\
\text { antara } \\
\text { kecepatan } \\
\text { pengembanga } \\
\text { n produk baru } \\
\text { terhadap } \\
\text { kesuksesan } \\
\text { produk baru, } \\
\text { berdasarkan } \\
\text { penelitian } \\
\text { tahun 1994- } \\
2012 .\end{array}$ & 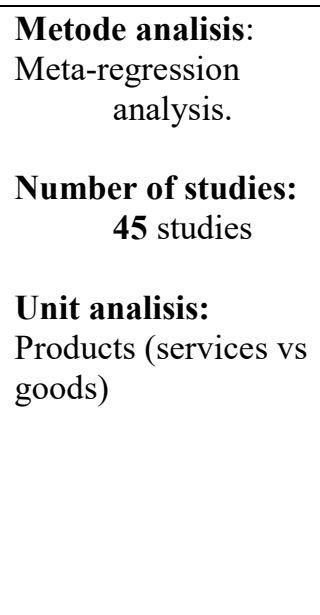 & $\begin{array}{l}\text { Development speed sangat } \\
\text { penting bagi kesuksesan } \\
\text { sebuah produk, walaupun } \\
\text { hasil empiris menunjukkan } \\
\text { hasil yang bertentangan } \\
\text { (conflicting). } \\
\text { Hasil menunjukkan bahwa } \\
\text { culture \& industry } \\
\text { characteristics, research } \\
\text { level, informants dan } \\
\text { variables measurement, } \\
\text { memiliki hubungan yang } \\
\text { moderat terhadap speed and } \\
\text { new product success. }\end{array}$ \\
\hline $\begin{array}{l}\text { Huang } \\
\& \text { Tsai } \\
(2013)\end{array}$ & $\begin{array}{l}\text { Antecedents of new } \\
\text { product performance: } \\
\text { 1. } \text { Strategy (e.g. } \\
\text { market orientation, } \\
\text { marketing synergy, } \\
\text { technological } \\
\text { synergy) } \\
\text { 2. Product } \\
\text { effectiveness (e.g. } \\
\text { product advantage, } \\
\text { product } \\
\text { innovativeness) } \\
\text { 3. Organization (e.g. } \\
\text { Cross-functional } \\
\text { integration, Top } \\
\text { management } \\
\text { support) } \\
\text { 4. Process (e.g. pre- } \\
\text { development } \\
\text { proficiency, } \\
\text { marketing } \\
\text { proficiency, } \\
\text { technological } \\
\text { proficiency, launch } \\
\text { proficiency) } \\
\text { Environment (e.g. } \\
\text { market potential, } \\
\text { market turbulence, } \\
\text { technological } \\
\text { turbulence, } \\
\text { competitive } \\
\text { intensity). }\end{array}$ & $\begin{array}{l}\text { Studi meta } \\
\text { analisis ini } \\
\text { mengukur } \\
\text { dampak } \\
\text { variabel- } \\
\text { variabel } \\
\text { penelitian } \\
\text { terhadap new } \\
\text { product } \\
\text { success, pada } \\
\text { pasar di Asia, } \\
\text { dan } \\
\text { membandingk } \\
\text { annya dengan } \\
\text { wilayah lain } \\
\text { (Amerika } \\
\text { utara, dan } \\
\text { Eropa). }\end{array}$ & $\begin{array}{l}\text { Metode analisis: } \\
\text { Meta-regression } \\
\text { analysis. } \\
\text { Number of studies: } \\
\quad \mathbf{1 0 6} \text { studies } \\
\text { Unit analisis: } \\
\text { Products } \\
\text { Lokasi studi: } \\
\text { Asia, Amerika utara, } \\
\quad \text { dan Eropa }\end{array}$ & $\begin{array}{l}\text { Studi ini menunjukkan } \\
\text { pendorong kesuksesan } \\
\text { produk diwilayah Asia } \\
\text { berbeda dengan wilayah } \\
\text { Amerika Utara dan Eropa. } \\
\text { Pada pasar Asia, kesuksesan } \\
\text { produk diperoleh oleh } \\
\text { perusahaan pada level } \\
\text { tinggi, serta menekankan } \\
\text { pada aspek market } \\
\text { orientation, marketing and } \\
\text { technological synergies, } \\
\text { cross-functio--nal } \\
\text { integration, pre- } \\
\text { development proficiency, } \\
\text { technological proficiency } \\
\text { dan top management } \\
\text { support. } \\
\text { Selain itu, dampak konteks } \\
\text { lingkungan terhadap } \\
\text { keberhasilan produk baru } \\
\text { untuk bisnis di Asia berbeda } \\
\text { dengan bisnis di wilayah } \\
\text { lain (Amerika utara, dan } \\
\text { Eropa). } \\
\text { Temuan penelitian ini } \\
\text { memperkuat perspektif } \\
\text { tentang pengembangan } \\
\text { produk baru, sehingga } \\
\text { perusahaan-perusahaan } \\
\text { yang beroperasi di Asia } \\
\text { dapat mempelajari implikasi } \\
\text { penting dari temuan-temuan } \\
\text { ini. }\end{array}$ \\
\hline
\end{tabular}


Aspek management \& organizational characteristics (karakteristik manajemen \& organisasi) adalah bentuk kebijakan dan sistem pengelolaan organisasi sehingga mampu menciptakan produk yang berkualitas. Terdiri atas prediktor organizational climate, organizational design, external relations, degree of centralization, degree of formalization, teamwork advance, crossfunctional integration, dan top/senior management support (Henard \& Szymanski, 2001; Evanschitzky et al., 2012; Cankurtaran et al., 2013; Huang \& Tsai, 2013; Fortuin et al., 2007; Lin, 2007; Peters et al., 2016; Liao et al., 2007; Junfeng \& Wei-Ping, 2017; Wu \& Wu, 2015; Johnson \& Filippini, 2013; Wu \& Chiu, 2015; Pee \& Kankanhalli, 2016; Valle \& Vazquez-Bustelo, 2009; Storey \& Easingwood, 1996).

Aspek marketplace characteristics (karakteristik pasar) mencakup semua eleman lingkungan pasar dimana organisasi berada, antara lain target pasar, potensi pasar, hingga aktivitas persaingan pasar. Aspek ini terdiri atas market orientation, customer input, market potential, dan environmental uncertainty (Henard \& Szymanski, 2001; Evanschitzky et al., 2012; Cankurtaran et al., 2013; Huang \& Tsai, 2013; Langerak et al., 2004; Calantone \& Di Benedetto, 2007; Junfeng \& WeiPing, 2017; Fortuin et al., 2007).

Selain 3 (tiga) aspek hasil studi meta analisis, terdapat 2 (dua) aspek lainnya yang berkorelasi dengan kesuksesan produk, yakni aspek knowledge sharing (berbagi pengetahuan) dan aspek innovation (inovasi). Kedua aspek ini dibangkitkan dari studi literature review secara sistematis dan mendalam. Kedua aspek memiliki dampak yang bersamaan, sebab pada kenyataannya kegiatan knowledge sharing dapat meningkatkan innovation capability yang akan berdampak terhadap kesuksesan produk (Huizingh, 2011; Lin \& Chen, 2007; Oke et al., 2007; Liao et al., 2007). Knowledge sharing juga berdampak langsung terhadap kesuksesan perusahaan, sebab kesuksesan sebuah perusahaan dihasilkan oleh para individu yang saling bertukar pengetahuan dan berkolaborasi secara sinergis untuk mencapai tujuan perusahaan (Jacobson, 2011).

Knowledge sharing merupakan suatu budaya interaksi sosial, dengan mempertukarkan pengetahuan dan informasi antar individu di dalam dan diluar organisasi, yang terdiri atas prediktor knowledge donating dan knowledge collecting (Nonaka \& Takeuchi, 1995; Nonaka \& Konno, 1998; Hooff \& Ridder, 2004; Bock et al., 2005; Hooff \& Weenen, 2004; Lin, 2007). Adapun aspek innovation terdiri atas prediktor product innovation, dan process innovation (Baregheh, Rowley, \& Sambrook, 2009; C. Y. Lin \& Chen, 2007; Oke et al., 2007; Rowley, Baregheh, \& Sambrook, 2011; Tomlinson \& Fai, 2013).

\subsection{Posisi Penelitian}

Berdasarkan systematic literature review, terdapat 3 (tiga) variabel yang dibangkitkan dari studi-studi meta-analisis sebelumnya yakni variabel product characteristics, management \& organizational characteristics, dan marketplace characteristics. Adapun variabel innovation dan knowledge sharing, dibangkitkan berdasarkan literatur berbasis review dan studi kasus. Posisi penelitian ini dibandingkan dengan penelitianpenelitian terdahulu, berdasarkan variabel-variabel yang digunakan dan metodanya, ditampilkan pada Tabel 1.

Tabel 2. Posisi penelitian

\begin{tabular}{|c|c|c|c|c|}
\hline & \multirow[b]{2}{*}{ Variables } & \multicolumn{3}{|c|}{ Method } \\
\hline & & Meta-analysis & Case Study & $\begin{array}{c}\text { Literature } \\
\text { Review/ } \\
\text { Theory/ } \\
\text { Conceptual }\end{array}$ \\
\hline \multirow{7}{*}{ 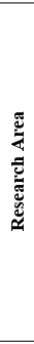 } & Product characteristics & $\begin{array}{l}\text { (1) (3) (4) (6) } \\
\text { (7) }(\end{array}$ & $\begin{array}{l}(8)(9)(10) \\
(11)\left({ }^{* *}\right)\end{array}$ & (26) \\
\hline & Management \& organizational char. & $\begin{array}{l}(1)(3)(4) \\
(* *)\end{array}$ & $\begin{array}{l}\text { (8) (14) (15) } \\
\text { (16) (21) }(* *)\end{array}$ & (26) \\
\hline & Marketplace characteristics & $\begin{array}{l}\text { (1) (4) (5) (6) } \\
(7)(* *)\end{array}$ & $\begin{array}{l}(8)(14)(16) \\
(* *)\end{array}$ & \\
\hline & Strategy characteristics & (1) (3) (7) & (12) & \\
\hline & Other & $\begin{array}{l}\text { (1) (2) (3) (4) } \\
\text { (5) (7) }\end{array}$ & (11) (12) & \\
\hline & Innovation & (6) (23) (24) & $\begin{array}{l}\text { (9) }(10)(11) \\
(14)(18)(19) \\
(21)(* *)\end{array}$ & $\begin{array}{l}\text { (13) (17) (23) } \\
\text { (24) (25) }\end{array}$ \\
\hline & Knowledge sharing & & $\begin{array}{l}(19)(20)(21) \\
(22)(* *)\end{array}$ & (23) (25) \\
\hline
\end{tabular}

Keterangan: $1=($ Evanschitzky et al., 2012); $2=($ Gao et al., 2013); $3=$ (Huang \& Tsai, 2013); $4=$ (Suharyanti, Subagyo, Masruroh, \& Bastian, 2015); $5=$ (Eisend et al., 2016); $6=$ (Cankurtaran et al., 2013); 7 = (Henard \& Szymanski, 2001); $8=$ (Langerak et al., 2004); 9 = (Valle \& Vazquez-Bustelo, 2009); 10 $=($ Gonzalez \& Vazquez, 2007); $11=$ (Junfeng \& Wei-Ping, 2017); 12 = (Johnson \& Filippini, 2013); $13=($ Jalonen, 2012); $14=($ I. Wu \& Chiu, 2015); $15=($ Pee \& Kankanhalli, 2016); 16 $=($ Roger J. Calantone \& Di Benedetto, 2007); $17=($ Huizingh, 2011); $18=($ Tomlinson \& Fai, 2013); $19=($ Liao et al., 2007); 20 $=($ Hooff $\&$ Ridder, 2004); $21=($ H.-F. Lin, 2007); $22=($ Casimir, Lee, \& Loon, 2012); 23 = (Szymanski, Kroff, \& Troy, 2007); 24 $=($ Rosenbusch, Brinckmann, \& Bausch, 2011); $25=($ Lasalewo, Subagyo, Hartono, \& Yuniarto, 2016); 26 = (Johansson, 2002); ** = studi ini

\section{KESIMPULAN DAN REKOMENDASI}

Kesuksesan produk sangat mempengaruhi kinerja bisnis suatu perusahaan/industri, sehingga setiap perusahaan berusaha menciptakan produk yang sukses di pasar. Sayangnya, tidak semua produk yang dihasilkan, akan berakhir dengan kesuksesan. Banyak hasil studi/survei yang menunjukkan hanya hanya sedikit produk yang akan sukses, dari banyak produk yang berhasil dikembangkan perusahaan dan launching di pasar.

Studi ini berupaya membangkitkan dan menganalisis aspek (variabel) yang mempengaruhi kesuksesan produk, melalui studi literatur mendalam dan sistematis (systematic literature review) agar dapat dijadikan sebagai bahan pertimbangan untuk mengembangkan produk di masa yang akan datang. Studi ini terutama mengkaji aspek-aspek yang memiliki dampak langsung terhadap kesuksesan produk, menggunakan 
pendekatan studi meta-analisis. Berdasarkan studi literatur sistematis ini, menemukan 5 (lima) aspek yang berdampak langsung terhadap kesuksesan sebuah produk, yakni: (1) product characteristics, (2) management \& organizational characteristics, (3) marketplace characteristics, (4) innovation dan (5) knowledge sharing. Melalui pendalaman studi literatur, kelima aspek ini selanjutnya diturunkan menjadi prediktor-prediktor, dengan total 20 prediktor. Adanya lima aspek dan dua puluh prediktor ini, dapat dijadikan sebagai model rujukan pengambilan keputusan, dalam rangka mengembangkan produk baru dimasa yang akan datang.

\section{DAFTAR PUSTAKA}

Baregheh, A., Rowley, J., \& Sambrook, S. (2009). Towards a Multidisciplinary Definition of Innovation. Management Decision, 47(8), 1323-1339.

Bock, G., Robert, W., \& Kim, Y. (2005). Behavioral Intention Formation in Knowledge Sharing: Examining the Roles of Extrinsic Motivators, Social-Psychological Forces, and Organizational Climate. MIS Quarterly, 29(1), 87-111.

Bouchereau, V., \& Rowlands, H. (2000). Methods and Techniques to Help Quality Function Deployment (QFD). Benchmarking: An International Journal, 7(1), 8-19.

Calantone, R. J., Schmidt, J. B., \& Song, X. M. (1996). Controllable Factors of New Product Success: A Cross-National Comparison. Marketing Science, 15(4), 341-358.

Calantone, Roger J., \& Di Benedetto, C. A. (2007). Clustering Product Launches by Price and Launch Strategy. Journal of Business \& Industrial Marketing, 22(1), 4-19.

Cankurtaran, P., Langerak, F., \& Griffin, A. (2013). Consequences of New Product Development Speed: A Meta-Analysis. Journal of Product Innovation Management, 30(3), 465-486.

Casimir, G., Lee, K., \& Loon, M. (2012). Knowledge Sharing: Influences of Trust, Commitment and Cost. Journal of Knowledge Management, 16(5), 740-753.

Cooper, R. G. (1980). Project NewProd : Factors in New Product Success. European Journal of Marketing, 14(5/6), 277-292.

Cooper, R. G. (2007). Doing it Right: Winning with New Products. Innovation Framework Technologies, 1-13. Retrieved from www.innovation-framework.com

Cooper, R. G., \& Kleinschmidt, E. J. (1987a). Success Factors in Product Innovation. Industrial Marketing Management, 16(3), 215-223.

Cooper, R. G., \& Kleinschmidt, E. J. (1987b). What Makes a New Product a Winner: Success factors at the Project Level. $R \& D$ Management, 17(3), 175-189.

Eisend, M., Evanschitzky, H., \& Calantone, R. J. (2016). The Relative Advantage of Marketing Over Technological Capabilities in Influencing New Product Performance: The Moderating Role of Country Institutions. Journal of International Marketing, 24(1), 41-56.

Evanschitzky, H., Eisend, M., Calantone, R. J., \& Jiang, Y. (2012). Success Factors of Product Innovation: An Updated Meta-Analysis. Journal of Product Innovation Management, 29, 21-37.

Fortuin, F. T. J. M., Batterink, M. H., \& Omta, S. W. F. (2007). Key Success Factors of Innovation in Multinational. International Food and Agribusiness Management Review, 10(4), 124.

Gao, P., Yu, B., \& Wu, W. (2013). The Impact of Development Speed on New Product Success: A Meta-Analysis. Applied Mechanics and Materials, 357-360, 2574-2577.

Gonzalez, B. U., \& Vazquez, J. M. C. (2007). The Strategic Influence of Structural Manufacturing Decisions. International Journal of Operation \& Production Management, 27(6), 605-626.

Henard, D. H., \& Szymanski, D. M. (2001). Why Some New Products Are More Successful Than Others. Journal of Marketing Research, 38(3), 362-375.

Hooff, B. Van Den, \& Ridder, J. a. De. (2004). Knowledge Sharing in Context: The Influence of Organizational Commitment, Communication Climate and CMC use on Knowledge Sharing. Journal of Knowledge Management, 8(6), 117-130.

Hooff, B. van den, \& Weenen, F. de L. van. (2004). Committed to Share: Commitment and CMC Use as Antecedents of Knowledge Sharing. Knowledge and Process Management, 11(1), 13-24.

Huang, S. C.-T., \& Tsai, K.-H. (2013). Exploring the Drivers of New Product Success for Businesses in Asia: a Meta-analysis. Asia Pacific Business Review, 19(3), 303-319.

Huizingh, E. K. R. E. (2011). Open Innovation: State of the Art and Future Perspectives. Technovation, 31(1), 2-9.

Hunter, J. E., \& Schmidt, F. L. (2004). Methods of Meta-Analysis: Correcting Error and Bias in Research Findings (2nd ed.). California: Sage Publications, Inc.

Jacobson, C. M. (2011). Knowledge Sharing Between Individuals. In D. Schwartz (Ed.), Encyclopedia of Knowledge Management (pp. 507-513). Idea Group Reference. Retrieved from books.google.co.id 
Jalonen, H. (2012). The Uncertainty of Innovation: a Systematic Review of the Literature. Journal of Management Research, 4(1), 1-47.

Jesson, J. K., Matheson, L., \& Lacey, F. M. (2011). Doing Your Literature Review: Traditional and Systematic Techniques (1st ed.). London: SAGE Publications Ltd.

Johansson, G. (2002). Success Factors for Integration of Ecodesign in Product Development: A Review of State of The Art. Environmental Management and Health, 13(1), 98-107.

Johnson, W. H. A., \& Filippini, R. (2013). Integration Capabilities as Mediator of Product Development Practices-Performance. Journal of Engineering and Technology Management, 30, 95-111.

Junfeng, Z., \& Wei-Ping, W. (2017). Leveraging Internal Resources and External Business Networks for New Product Success: A Dynamic Capabilities Perspective. Industrial Marketing Management, 61, 170-181.

Langerak, F., Hultink, E. J., \& Robben, H. S. J. (2004). The Impact of Market Orientation, Product Advantage, and Launch Proficiency on New Product Performance and Organizational Performance. Journal of Product Innovation Management, 21(2), 7994.

Lasalewo, T., Subagyo, Hartono, B., \& Yuniarto, H. A. (2016). Communication Constraints and Motivations in the Context of Knowledge Sharing: A Systematic Literature Review. In IEEE International Conference on Industrial Engineering and Engineering Management (IEEM) (pp. 1804-1808). Bali: IEEE.

Liao, S. H., Fei, W. C., \& Chen, C. C. (2007). Knowledge Sharing, Absorptive Capacity, and Innovation Capability: an Empirical Study of Taiwan's Knowledge-Intensive Industries. Journal of Information Science, 33(151), 340-359.

Lin, C. Y., \& Chen, M. Y. (2007). Does Innovation Lead to Performance? An Empirical Study of SMEs in Taiwan. Management Research News, 30(2), 115-132.

Lin, H.-F. (2007). Knowledge Sharing and Firm Innovation Capability: An Empirical Study. International Journal of Manpower, 28(3), 315-332.

Lin, L. (2007). Applying Fuzzy Set Theory on New Product Launch Decisions for Internet Commerce. In International Conference on Innovative Computing, Information and Control (ICICIC) 2007 (p. 436). Kumamoto, Japan: IEEE.

Nonaka, Ikujiro, \& Konno, N. (1998). The Concept of "Ba": Bulding a Foundation for Knowledge Creation. California Management Review,
40(3), 40-54.

Nonaka, Ikujirō, \& Takeuchi, H. (1995). The Knowledge-Creating Company: How Japanese Companies Create the Dynamics of Innovation. Oxford university press.

Oke, A., Burke, G., \& Myers, A. (2007). Innovation Types and Performance in Growing UK SMEs. International Journal of Operations \& Production Management, 27(7), 735-753.

Pee, L. G., \& Kankanhalli, A. (2016). Interactions Among Factors in Fluencing Knowledge Management in Public-Sector Organizations: A Resource-based View. Government Information Quarterly, 33, 188-199.

Peters, M. D., Wieder, B., Sutton, S. G., \& Wakefield, J. (2016). Business Intelligence Systems use in Performance Measurement Capabilities: Implications for Enhanced Competitive Advantage. International Journal of Accounting Information Systems, 21, 1-17.

Rosenbusch, N., Brinckmann, J., \& Bausch, A. (2011). Is Innovation Always Beneficial? A Meta-analysis of the Relationship Between Innovation and Performance in SMEs. Journal of Business Venturing, 26, 441-457.

Rowley, J., Baregheh, A., \& Sambrook, S. (2011). Towards an Innovation-type Mapping Tool. Management Decision, 49(1), 73-86.

Schilling, M. A. (2013). Strategic Management of Technological Innovation (4th ed.). New York: McGraw-Hill Companies, Inc.

Storey, C. D., \& Easingwood, C. J. (1996). Determinants of New Product Performance: a Study in the Financial Services Sector. International Journal of Service Industry Management, 7(1), 32-55.

Suharyanti, Y., Subagyo, Masruroh, N. A., \& Bastian, I. (2015). The Role of Product Development to Drive Product Success: An Updated Review and Meta-Analysis. In Lecture Notes in Electrical Engineering (pp. 501-510). Berlin: Springer.

Szymanski, D. M., Kroff, M. W., \& Troy, L. C. (2007). Innovativeness and New Product Success: Insights from the Cumulative Evidence. Journal of the Academy of Marketing Science, 35(1), 35-52.

Tomlinson, P. R., \& Fai, F. M. (2013). The Nature of SME Co-operation and Innovation: A Multi-scalar and Multi-dimensional Analysis. International Journal of Production Economics, 141, 316-326.

Valle, S., \& Vazquez-Bustelo, D. (2009). Concurrent Engineering Performance: Incremental versus Radical Innovation. International Journal of Production Economics, 119, 136-148.

Wu, I., \& Chiu, M. (2015). Organizational 
Applications of IT Innovation and Firm's Competitive Performance: A Resource-Based View and the Innovation Diffusion Approach. Journal of Engineering and Technology Management, 35, 25-44.

Wu, J., \& Wu, Z. (2015). Key Supplier Relationships and Product Introduction Success: The Moderating Roles of SelfEnforcement and Interdependence between Buyer and Supplier. Industrial Marketing Management, 46, 183-192. 